Dicle Tıp Dergisi / Dicle Med J (2018) 45 (1) : 35 - 41

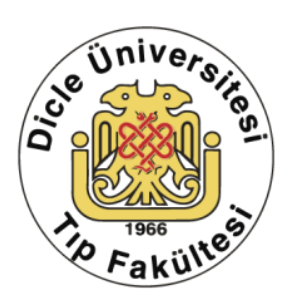

WWW.diclemedj.org

Özgün Araștırma / Original Article

\title{
Sigara Bırakma Polikliniğine Başvuran Hastaların Nikotin Bağımlılığının Sosyo demografik Özellikler ve Depresyon İle İliş̧kisi
}

\author{
Usame Velioğlư1, Cemil Işık Sönmez² \\ 1 Yı̆ğlca İlçe Devlet Hastanesi Düzce, Türkiye ORCID: 0000-0002-0165-2022 \\ 2 Düzce Üniversitesi Tıp Fakültesi Aile Hekimliği ABD, Düzce, Türkiye ORCID: 0000-0001-7854-3804
}

Geliş: 23.06.2017, Revizyon: 11.11.2017, Kabul Tarihi: 28.12.2017

Özet

Amaç: Bu çalışmada sigara bırakma polikliniğe başvuran hastaların sigara bağımlılıklarının sosyodemografik özellikler ve depresyon ile ilişkisini araştırmayı amaçladık.

Yöntemler: Bu retrospektif çalışmaya Sigara Bırakma Polikliniğine Mart 2015 - Kasım 2016 tarihleri arasında başvuran 2119 kişi dahil edildi. Fagerstrom Nikotin Bağımlılık Testi (FNBT) ve Beck Depresyon Ölçeği uygulanmış olan hastaların sosyo demografik özellikleri incelendi. Hastaların nikotin bağımlılığının sosyo demografik özellikler ve depresyon arasındaki ilişki incelendi.

Bulgular: Çalışmadaki hastaların 1468 (\%69,3)'i erkek, 651 (\%30,7)'i kadındı. Çalışmamızda cinsiyet, medeni durum, eğitim durumu, meslek durumu, ailede sigara kullanma durumunun FNBT skoru üzerine anlamlı etkisi olmadığı gözlendi. Yaş gruplarına göre nikotin bağımlılık düzeylerine bakıldığında"<20" yaş grubundaki nikotin bağımlılık düzeyi düşük olan bireylerin oranı, "41-50" ve "51-60" yaş gruplarındakilerden anlamlı düzeyde yüksekti(her biri için $\mathrm{p}<0,005)$. Alkol kullananların nikotin bağımlılığının daha yüksek olduğu anlamlı olarak görüldü $(\mathrm{p}=0,011)$. Nikotin bağımlılığı arttıkça depresyon düzeylerinin arttığı anlamlı olarak saptandı $(\mathrm{p}<0,001)$.

Sonuç: Nikotin bağımlılığının alkol ve depresyon ile ilişkisinin olduğu saptanmıştır. Nikotin bağımlılığı ile mücadelede, hastalar biyopsiko sosyal yaklaşımla değerlendirilmelidir. Sigara bıraktırma uygulamalarında özellikle genç popülasyon hedef alınmalıdır.

Anahtar kelimeler: Nikotin bağımlılı̆̆ı, sosyo demografik özellikler, sigara bırakma, depresyon

DOI: $10.5798 /$ dicletip.407242

Yazışma Adresi / Correspondence: Usame Velioğlu, Koçyazı Mah. Metektoki Konutları K6-10 Daire: 9 Düzce Posta Kodu: 81010 e-mail: usame87@yahoo.com.tr 


\title{
Relationship of Nicotine Dependence with Sociodemographic Characteristicsand Depression in The Patients Admitted to Smoking Cessation Clinic
}

\begin{abstract}
Objective: In this study, we aimed to investigate the relationship between cigarette addiction and socio-demographic characteristics and depression in patients who applied smoking cessation outpatient clinics.

Method: This retrospective study included 2119 patients who applied to Smoking Cessation Outpatient Clinic from March 2015 to November 2016. The socio-demographic characteristics of patients who were tested out Fagerstrom Test for Nicotine Dependence (FTND) and Beck Depression Scale, were examined. The relationship between nicotine dependence and socio-demographic characteristics and depression of patients was examined.

Results: 1468 (69.3\%) of the patients were male and 651 (30.7\%) were female. In our study, it was observed that gender, marital status, educational status, occupational status, family smoking status had no significant effect on FTND score. The nicotine addiction level in the "20" age group was significantly lower than the "41-50" and "51-60" age groups ( $\mathrm{p}<0.005$ for each). The nicotine addiction of alcohol users was found to be higher ( $\mathrm{p}=0.011)$. As nicotine addiction increased, depression levels were significantly increased $(\mathrm{p}<0.001)$.

Conclusion: Nicotine addiction was found to be related to alcohol and depression. In the struggle against nicotine addiction, patients should be evaluated with bio-psychosocial approach. In smoking cessation programs, especially young population should be targeted.
\end{abstract}

Keywords: Nicotine addiction; socio-demographic characteristics; smoking cessation; depression

\section{GİRIS}

Günümüzün en büyük problemlerinden birisi olan tütün kullanımı gittikçe yaygınlaşmakta olup, özellikle genç nüfus daha çok etkilenmektedir. İnsanlar psikolojik, sosyal ve farmakolojik faktörler yüzünden tütün kullanmaya başlamakta ve kullanmayı sürdürebilmektedirler. Birçok insan bunu günlük bir ihtiyaç olarak görmekte ve dünyanın her yerinde tütüne kolaylıkla ulaşabilmektedir. Resmi olarak tütün kullanmanın zararlı olabileceği görüşünü ilk kez Stanhope ve arkadaşları 1964 yılında Amerika Birleşik Devletleri'nde yayınlanan Surgeon General raporunda açıklamışlardır ${ }^{1}$. Dünya Sağlık Örgütü (DSÖ) açıklamalarına göre her sene 4 milyon kişi sigaranın neden olduğu hastalıklar sebebiyle hayatını kaybetmektedir; bu rakamın 2030 yılında 10 milyona ulaşacağı tahmin ediliyor ve 2020 'lerde ise sigaranın sebep olduğu ölümlerin \%70'inin gelişmekte olan ülkelerde olacağı öngörülmektedir ${ }^{1}$.

Türkiye'de erken yaşta ölümlere sebep olan malignitelerin ve kardiyovasküler sistem hastalıklarının en önemli sebeplerinden biri de sigaradır. Öte yandan sigara kontrol edilebilir ve önlenebilir nedenlerdendir. Sigara bağımlılı̆̆ının bir hastalık olduğu DSÖ tarafından kabul edilmiștir. Bu yüzden tütün kullanımıyla tüm hekimler mücadele etmeli ve tütün kullanan kişilerin bırakması için teşvik edilmelidir.

Sigaranın yaptığı tahribata bakacak olursak hem insanların hem de devletlerin bütçelerine büyük bir yük oluşturduğu görülmektedir. Ayrıca sigaranın içinde bulunan zararlı maddelere ve yaptıkları etkilere bakacak olursak, insan organizmasına ne kadar zararlı olduğu görülmektedir. Sigara içme durumlarının bugünkü gibi devam etmesi halinde önümüzdeki 30 yıl içerisinde sigara nedenli ölümlerin, tüberküloz, anne ölümleri, trafik kazaları, kazanılmış immün yetmezlik sendromu (AIDS), intihar ve cinayetlere bağlı ölümlerin toplamını geçeceği öngörülmektedir ${ }^{2}$.

Depresyon aile hekimliğinde ikinci en slk görülen ruhsal sağllk problemidir. Depresyon duygusal, bilişsel ve güdüsel alanlarda birçok 
belirtiyi içermekte olup, kronikleşme, yaygınlık ve tekrarlama oranın yüksek olması, iş gücü kaybının yanında intihar riskini de arttırması gibi nedenlerden dolayı önemli olan bireysel ve toplumsal bir sağlık problemidir ${ }^{3-5}$. Öte yandan, psikiyatrik bozuklukları olan ülkemizdeki hastaların yaklaşık yarısının, tüm literatüre bakıldığında ise psikiyatrik hastaların \%4090’ının sigara bağımlısı olduğu bilinmektedir6.

Çalışmamızda sigara bırakma polikliniğe başvuran hastaların sigara bağımlılıklarının sosyo demografik özellikler ve depresyon ile ilişsisini araştırmayı amaçladık.

\section{YÖNTEMLER}

Çalışmaya Sigara Bırakma Polikliniğine Mart 2015-Kasım 2016 tarihleri arasında başvuran 2119 hasta dahil edilmiştir. Çalışmaya sigara bırakma polikliniğinin açıldığı tarihten itibaren hastalar toplanmıştır. $\mathrm{Bu}$ retrospektif klinik çalışma için Etik Kuruldan onay alınmıştır. Tarafımızca hazırlanan hasta takip formu ile değerlendirilen hastalar çalışmaya alındı.

Hasta takip formundaki sorular her gelen hastaya sorulmakta olup, bu çalışmamamızda sosyo demografik özellikler kullanılmıștır. Sosyo demografik özelliklerden yaş, cinsiyet, meslek, eğitim durumu, alkol kullanımı, medeni durum ve ailede sigara içme öyküsüne bakıldı.

Sigara bırakma polikliniğine başvuran hastalara Fagerstrom Nikotin Bağımlılık Testi yapılmakta olup bu çalışmamızda kullanıldı. 6 sorudan oluşan bu testten 0-2 puan alanlar 'çok düşük düzey', 3-4 puan alanlar 'düşük düzey', 5 puan alanlar 'orta düzey', 6-7 puan alanlar 'yüksek düzey', 8-10 puan alanlar 'çok yüksek düzey' nikotin bağımlısı olarak kabul edildi.

Sigara bırakma polikliniğimizde hastaları değerlendirmek amacıyla uyguladığımız bir diğer test ise Beck Depresyon Ölçeğidir. Bu çalışmamızda hastaların Beck Depresyon Düzeylerine de bakılmıştır. Beck depresyon ölçeğinde 21 soru bulunmaktadır. Toplam değer 9 ve daha az ise "depresyon yok/minimal depresyon", 10-16 ise "hafif", 17-29 ise "orta",
30 ve yukarısı "şiddetli depresyon" olarak değerlendirildi.

Verilerin bilgisayar ortamına aktarılmasinı takiben istatistiksel analizler gerçekleştirildi. Çalışmadaki verilerin tanımlayıcı istatistikleri hesaplandı. Gruplar arası karşılaştırmada Kruskal Wallis ve Mann-Whitney U testleri (Post Hoc Dunn test) kullanıldı. Kategorik değişkenler arası ilişkilerde Pearson Chi-square ve Fisher Freeman Halton testleri kullanıldı. Değişkenler arası ilişkilerin incelenmesinde Kendall Tau-b katsayısı kullanıldı. İstatistiksel analizlerde SPSS 20.0 programı kullanıldı.

\section{BULGULAR}

Çalışmaya Sigara Bırakma Polikliniğine Mart 2015 - Kasım 2016 tarihleri arasinda başvurmuş 2119 kişi alındı. Örneklem grubunun yaş aralı̆̆ $15-87$ arasında değişmekte olup, yaş ortalaması $38,4 \pm 12,5$ 'ti. Bir hastanın yaşı kaydedilmemiş̦ti. Örneklem grubunun \%3'ünün 19 ve aşağı, \%27,6'sının 20-30 arası, \%30,8'inin 31-40 arası, \%19,5'inin 41-50 arası, \%13,4'ünün 51-60 arası, $\% 5,7$ 'sinin 61 ve üzeri yaşa sahip olduğu görüldü. Örneklem grubunun 1468 (\%69,3)'i erkek, $651 \quad(\% 30,7)$ 'i kadındı. Çalışmaya katılanların medeni durumlarına baktığımızda $1641(\% 77,4)$ evli, 384 (\%18,1) bekar, 94 $(\% 4,4)$ dul veya boşanmıştı.

Çalışmaya katılanların eğitim düzeyi; 483 $(\% 22,8)$ üniversite ve üstü, $645(\% 30,5)$ lise mezunu, $267(\% 12,6)$ ortaokul mezunu, 708 $(33,5)$ ilkokul mezunu olup, $12(\% 0,06)$ kişi okur-yazar değildi. Çalışmaya katılan kişilerin meslek gruplarına göre dağılımı şöyleydi; 297 (\%14) memur, 735 (\%34,7) işçi, $291(\% 13,8)$ serbest, $48 \quad(\% 2,3)$ çiftçi, $370 \quad(\% 17,5)$ ev hanımı, 129 (\%6,1) öğrenci, 196 (\%9,3) emekli, $50(\% 2,4)$ çalışmıyor veya düzensiz. Çalışmaya katılan kişilerin $426 \quad(\% 20,1)$ 'i alkol kullanmakta, $1693 \quad(\% 79,9) ' u ̈$ ise alkol kullanmamaktaydı.

Çalışmaya katılan kişilerin yaşadıkları evde başka sigara kullanan olup olmadığına 
bakıldığında; 972 (\%45,9) kișinin evinde hiç kimse sigara içmez iken, $77(\% 3,6)$ kişinin babası, 30 (\%1,4) kişinin annesi, 59 (\%2,8) kişinin kardeşi, 469 (\%23,4) kişinin eşi, 8 $(\% 0,06)$ kişinin arkadaşı, 57 (\%2,7) kişinin babası ve kardeși, 22 (\%1,0) kişinin annesi ve kardeşi, 32 (\%1,5) kişinin annesi ve babası, 22 $(\% 1,0)$ kişinin anne, baba ve kardeşi, 134 $(\% 6,3)$ kişinin eşi ve çocuğu sigara kullanmaktaydı.

Örneklem grubunun Fagerstrom Nikotin Bağımlılık Testi skor dağılımına bakıldığında, 196 (\%9,2) kişinin çok düşük, $475(22,4)$ kişinin düşük, $347(\% 16,4)$ kişinin orta, 663 (\%31,3) kişinin yüksek, 438 (\%20,7) kişinin çok yüksek çıkmıştır. Beck depresyon düzeylerine bakıldığında ise $689(\% 33,7)$ kișide depresyon olmadığı, 599 (\%29,3) kişide hafif, $570(\% 27,9)$ kişide orta, 188 (\%9,2) kişide şiddetli depresyon görüldü.

Yaş gruplarına göre nikotin bağımlılık düzeyleri arasında anlamlı düzeyde fark vardır $(\mathrm{p}=0,002) . \quad "<20 "$ yaş grubundaki nikotin bağımlılık düzeyi düşük olan bireylerin oranı (\%34,9), "41-50" ve "51-60" yaş gruplarındaki nikotin bağımlılık düzeyi düşük olan bireylerin oranlarından (\%18,2-\%17,3) anlamlı düzeyde daha yüksektir (her biri için $\mathrm{p}<0,005$ ). "41-50" yaş grubunda nikotin bağımlılık düzeyleri çok yüksek olan bireylerin oranı $(\% 25,2) "<20$ " yaş grubunda nikotin bağımlılık düzeyi yüksek olanların oranından $(\% 7,9)$ anlamlı düzeyde daha yüksektir (Tablo 1, p<0,05).

Cinsiyete, eğitim durumuna, medeni duruma ve ailede sigara içme durumuna göre nikotin bağımlılığı arasında anlamlı farklılık yoktu.

Alkol kullanma durumu ile nikotin bağımlılık düzeyleri arasında anlamlı farklılık vardır (P:0,011). Tablo 2'de gösterilmiştir. Alkol kullanıp nikotin bağımlılı̆̆ı çok yüksek olanların oranı $(\% 24,2)$, alkol kullanmayıp nikotin bağımlılığı çok olanların oranından $(\% 19,8)$ anlamlı olarak yüksektir. Alkol kullanıp nikotin bağımlılığı yüksek olanların oranı $(\% 35,4)$, alkol kullanmayıp nikotin bağımlılığı yüksek olanların oranından $(\% 30,2)$ anlamlı olarak yüksektir. Alkol kullanmayıp nikotin bağımlılı̆̆ı düşük olanların oranı $(\% 23,5)$, alkol kullanıp nikotin bağımlılığı düşük olanların oranından $(\% 18,1)$ anlamlı olarak yüksektir.

Nikotin bağımlılık düzeylerine göre Beck depresyon testi median değerleri Tablo 3'de verilmiştir. Nikotin bağımlılık düzeyleri çok düşük-orta (P:0,05), çok düşük-yüksek $(\mathrm{P}<0,01)$, çok düşük-çok yüksek $(\mathrm{P}<0,01)$, düşük-yüksek $(\mathrm{P}<0,01)$, düşük-çok yüksek $(\mathrm{P}<0,01)$, orta-çok yüksek $(\mathrm{P}<0,01)$, yüksek-çok yüksek $(\mathrm{P}<0,01)$ grupları arasında anlamlı farklılık vardır. Nikotin bağımlılık düzeyleri ile Beck depresyon testi değerleri arasında pozitif ilişki olduğu görülmüştür (Kendall'stau-b, $r=0,150 \mathrm{p}<0,001)$.

\section{TARTIŞMA}

Yaptığımız çalışmada sigara polikliniğine erkeklerin daha fazla başvurduğu görülmüştür. Yapılan bir çok çalışmada da sigara bırakma polikliniğine başvuran erkeklerin sayısı fazla bulunmuştur $^{7-9}$. Bunun sebebi ülkedeki sigara içme prevelansının erkeklerde daha fazla olduğuna bağlanabilir ${ }^{10}$. Fakat Salepçi ve ark. ve Wilson ve ark.'nın yaptığı çalışmalarda kadın oranı daha yüksek çıkmıştır ${ }^{11,12}$. Demir ve ark.'nın yaptığı çalışmada ise kadın-erkek oranı birbirine çok yakın bulunmuştur ${ }^{13}$.

Çalışmamızda 20 yaş altı kişilerin nikotin bağımlılıkları daha düşük çlkmıştı. Bunun sebebi, sigara kullanma süresinin az olmasına bağlanabilir. Çelebkolu ve ark.'nın yapmış olduğu çalışmada yaş ile bağımlılık düzeyi arasında anlamlı ilişki bulunmamasına rağmen 50 yaş ve üzeri grubunda yüksek bağımlılık düzeyi \%53,5 iken 20-39 yaş grubunda bu oran \%45,9'a düşmekteydi. Ayrıca istatistiksel olarak anlamlı olmasa da ileri yaşlara doğru erken yaş gruplarına göre bağımlılık oranlarını daha fazla bulmuşlardı ${ }^{14}$. Kaptanoğlu ve ark.'nın çalışmasında ise, yaş ile bağımlılık düzeyi arasında pozitif korelasyon olduğunu ve anlamlı ilişki bulduklarını söylemişlerdi ${ }^{15}$. Bu 
durum yaş ilerledikçe kullanılan sigara miktarı ve süresinin artmasına bağlanabilir.

Çalışmamızda alkol kullanan bireylerin nikotin bağımlılık düzeylerinin, alkol kullanmayanlara göre daha yüksek olduğu anlamlı olarak görüldü (Tablo 1). Grucza ve Bierut'un yapmış olduğu bir çalışmada sigara içen kişilerin alkol kullanmaya daha meyilli oldukları görülmüştür ${ }^{16}$. Tanrıkulu ve ark.'nın Kars ilinde öğrencilerle yapmış olduğu çalışmada da sigara ile alkol ve uyuşturucu madde kullanımı arasında güçlü bir ilişki saptanmıştır ${ }^{17}$. Ankara'da yapılan bir çalışmada sigara bırakma polikliniğine başvuru yapanların yaklaşık \%40'ında alkol kullanımının da olduğu saptanmıştır ${ }^{18}$. İzmir'de yapılan bir çalışmada ise alkol kullanan kişilerde yüksek oranda sigara içiciliği saptanmıştır ${ }^{19}$. Kayseri'de yapılan bir çalışmada da sigara içenlerin çay, kahve ve alkolü anlamlı olarak daha fazla tükettikleri gösterilmiştir ${ }^{19}$. $\mathrm{Bu}$ bulgular, literatürde yer alan bağımlılıkların birbirlerini tetiklemesi ile ilişkili olabilir.

Yapılan korelasyon analizine göre, çalışmamıza katılanların nikotin bağımlılık düzeylerinin arttıkça Beck depresyon testi değerlerinin de arttığı anlamlı olarak saptanmıştır (Tablo 2). Grant ve ark.'nın yapmış olduğu çalışmada major depresyonu olup nikotin bağımlılığı olanların oranı \%30,01 bulunmuştur ${ }^{20}$. Manley ve ark.'nın yapmış oldukları bir çalışmada şiddetli nikotin bağımlısı olanların, günlük içiciler ve hafif içicilere göre depresyona yatkınlıklarının daha fazla olduğu bulunmuştur ${ }^{21}$. Rezvanfard ve ark.'nın yapmış olduğu bir çalışmada hastaları sigara içmeyenler, düşük bağımlılılar ve yüksek bağımlılar olmak üzere 3 gruba ayırmışlar ve nikotin bağımlılığı arttıkça depresyon düzeylerinin anlamlı bir şekilde arttığını bizim çalışmamıza benzer bir şekilde bulmuşlardır ${ }^{22}$. Sigara kullanımı geçici bir kendini iyi hissetme durumu sağlamaktadır. Depresyon arttıkça sigara kullananlar bir kaçış yolu olarak sigara kullanımını arttırmaya meyilli olabileceği düşünüldü. Bununla birlikte sigara bağımlılığı ve major depresyon birlikteliğinin sebepleri halen araştırılmaktadır ve kesin sonuçlara varılamamıştır. $\mathrm{Bu}$ iki sorunun arasındaki ilişkiyi ortaya koymak tedavi stratejileri geliştirmek açısından da faydalı olacaktır.

Tablo 1: Yaş gruplarına göre nikotin bağımlılık düzeyleri

\begin{tabular}{|c|c|c|c|c|c|c|c|c|}
\hline & \multicolumn{8}{|c|}{ Yaş Grupları } \\
\hline & & $\begin{array}{c}<20 \\
\mathrm{~N}(\%)\end{array}$ & $\begin{array}{l}20-30 \\
N(\%)\end{array}$ & $\begin{array}{l}31-40 \\
\mathrm{~N}(\%)\end{array}$ & $\begin{array}{c}41-50 \\
\mathrm{~N}(\%)\end{array}$ & $\begin{array}{l}51-60 \\
N(\%)\end{array}$ & $\begin{array}{c}61+ \\
N(\%)\end{array}$ & Total N(\%) \\
\hline \multirow{5}{*}{ FNBT } & $\begin{array}{l}\text { çok } \\
\text { düşük }\end{array}$ & $8(12,7)$ & $40(6,8)$ & $71(10,9)$ & $42(10,2)$ & $25(8,8)$ & $10(8,3)$ & $196(9,3)$ \\
\hline & düşük & $22(34,9)$ & $133(22,7)$ & $160(24,5)$ & $75(18,2)$ & $49(17,3)$ & $35(29,2)$ & $474(22,4)$ \\
\hline & orta & $14(22,2)$ & $99(16,9)$ & $91(13,9)$ & $69(16,7)$ & $59(20,8)$ & $15(12,5)$ & $347(16,4)$ \\
\hline & yüksek & $14(22,2)$ & $198(33,8)$ & $203(31,1)$ & $123(29,8)$ & $89(31,3)$ & $36(30,0)$ & $663(31,3)$ \\
\hline & $\begin{array}{l}\text { çok } \\
\text { yüksek }\end{array}$ & $5(7,9)$ & $115(19,7)$ & $128(19,6)$ & $104(25,2)$ & $62(21,8)$ & $24(20,0)$ & $438(20,7)$ \\
\hline Toplam & & $63(100)$ & $585(100)$ & $653(100)$ & 413(100) & $284(100)$ & $120(100)$ & $2118(100)$ \\
\hline
\end{tabular}

N: Birey Sayısı FNBT: Fagerstrom Nikotin Bağımlılık Testi 
Tablo 2: Alkol kullanma durumuna göre nikotin düzeyleri

\begin{tabular}{|ccccc|}
\hline \multicolumn{4}{c}{ Alkol Durumu } \\
& Kullanıyor N (\%) & Kullanmıyor N (\%) & Toplam \\
\hline düşük & $77(18,1)$ & $398(23,5)$ & $475(22,4)$ \\
orta & $62(14,6)$ & $285(16,8)$ & $347(16,4)$ \\
FNBT & yüksek & $151(35,4)$ & $512(30,2)$ & $663(31,3)$ \\
& çok yüksek & $103(24,2)$ & $335(19,8)$ & $438(20,7)$ \\
\hline & Toplam & $426(100)$ & $1693(100)$ & $2119(100)$ \\
\hline
\end{tabular}

N: Birey Sayısı FNBT: Fagerstrom Nikotin Bağımlılık Testi

Tablo 3: Nikotin bağımlılık düzeylerine göre Beck depresyon testi median değerleri

\begin{tabular}{|llccccc|}
\hline & & N & Median & Minimum & Maximum & $\mathrm{p}$ \\
\hline \multirow{2}{*}{ çok düşük } & 183 & 10,00 & 0 & 42 & \\
düşük & 459 & 12,00 & 0 & 51 & \\
FNBT & orta & 333 & 12,00 & 0 & 50 & $<0,001$ \\
& çüksek & 647 & 14,00 & 0 & 49 & \\
& yüksek & 424 & 17,00 & 0 & 50 & \\
& Toplam & 2046 & 13,00 & 0 & 51 & \\
\hline
\end{tabular}

N: Birey Sayısı FNBT: Fagerstrom Nikotin Bağımlılık Testi p:Korelasyon için anlamlılık değeri

SONUÇ

Çalışmamızda gençlerin bağımlılıklarının düşük olduğu görüldü. Alkol kullanan kişilerin nikotin bağımlılık düzeylerinin daha fazla olduğu görüldü. Çalışmamızda nikotin bağımlılık düzeyleri arttıkça depresyon oranlarının arttığı gözlemlendi.

Sonuç olarak depresyon ve alkol kullanımının nikotin bağımlılı̆̆ ile ilişkisi olduğu görüldü. $\mathrm{Bu}$ nedenle hastalara yaklaşırken aile hekimliğinin temel kavramlarından olan biyopsikososyal yaklaşım akılda tutulmalı, hastalar bütüncül olarak değerlendirilmelidir. Öte yandan, bağımlılıkları henüz gelişmemiş olan genç kitlenin sigara ile mücadelede özellikle hedef alınması faydalı bir eylem olacaktır.

Sunulduğu kongre: 6. Uluslararası Trakya Aile Hekimliği Kongresi'nde sözel bildiri olarak sunuldu.
Çıkar Çatışması Beyanı: Yazarlar çıkar çatışması olmadığını bildirmişlerdir.

Finansal Destek: Bu çalışma her hangi bir fon tarafından desteklenmemiştir.

Declaration of Conflicting Interests: The authors declare that they have no conflict of interest.

Financial Disclosure: No financial support was received.

\section{KAYNAKLAR}

1. World Health Organization, World Health Report 1999. Geneva: WHO. 1999.

2. Fiore MC. A clinical practice guideline for treating tobacco use and dependence: a US Public Health Service report. JAMA: Journal of the American Medical Association. 2000 Jun 28;283(24):3244-54.

3. Berg AM, Hem E, Lau B, Haseth K, Ekeberg O. Stress in the Norwegian police service. Occupational medicine. 2005; 55:113-20. 
4. Kirkcaldy B, Shephard R. Occupational stress, work satisfaction and health among the helping professions. European Review of Applied Psychology/Revue Européenne de Psychologie Appliquée. 2001; 51(4), 243-253.

5. Kohan A, O'connor BP. Police officer job satisfaction in relation to mood, well-being, and alcohol consumption. The Journal of psychology. 2002;136:307-18.

6. Ertekin H, Aydın M, Arslan M, Ertekin YH, Eren İ. Psikiyatri Polikliniğine Başvuran Hastaların Sigara Kullanımı Değerlendiriliyor Mu? Konuralp Tip Dergisi. 2017;9:78-82.

7. Barbano G, Bressan M, Nardini S. The stage-of-change model in smoking cessation in respiratory patients: does it need to be revisited. Smoking Cessation Sheffield, UK: European Respiratory Society Journals Ltd. 2008;42:51-6.

8. Godtfredsen $\mathrm{N}$, Lam T, Hansel T, Leon M, Gray N, Dresler C, et al. COPD-related morbidity and mortality after smoking cessation: status of the evidence. European Respiratory Journal. 2008;32:844-53.

9. Gómez FP, Rodriguez-Roisin R. Global Initiative for Chronic Obstructive Lung Disease (GOLD) guidelines for chronic obstructive pulmonary disease. Current opinion in pulmonary medicine. 2002;8:81-6.

10. TC Temel Sağlık Hizmetleri Genel Müdürlüğü. Küresel yetişkin tütün araștırması Türkiye raporu 2010. Ankara: Anıl Matbacılık. 2010:37-75.

11. Tønnesen P, Carrozzi L, Fagerström K, Gratziou C, Jimenez-Ruiz C, Nardini S, et al. Smoking cessation in patients with respiratory diseases: a high priority, integral component of therapy. European Respiratory Journal. 2007;29:390-417.

12. Umut S, Saryal S. Türk Toraks Derneği Astım Tanı ve Tedavi Rehberi. Türk Toraks Dergisi. 2010;11:1-15.

13. Demir T, Tutluoğlu B, Koç N, Bilgin L. Sigara bırakma polikliniğimizin bir yıllık izlem sonuçları. Tüberküloz ve Toraks Dergisi. 2004;52:63-8.
14. Çelepkolu T, Atli A, Palancı Y, Yılmaz A, Demir S, İbiloğlu AO, et al. Sigara kullanıcılarda nikotin bağımlılık düzeyinin yaş ve cinsiyetle ilişkisi: Diyarbakır örneklemi. Dicle Tıp Dergisi. 2014;41:712-6.

15. Kaptanoğlu AY, Polat G, Soyer M. Marmara Üniversitesi öğrencilerinde ve öğretim üyelerinde sigara alışkanlığı ve durağan maliyet ilişkisi. Journal of Higher Education \& Science/Yüksekögretim ve Bilim Dergisi. 2012;2:119-25.

16. Grucza RA, Bierut LJ. Cigarette smoking and the risk for alcohol use disorders among adolescent drinkers. Alcoholism: Clinical and Experimental Research. 2006;30:2046-54.

17. Tanrıkulu AÇ, Çarman KB, Palancı Y, Çetin D, Karaca M. Kars Il Merkezinde çeşitli üniversite öğrencileri arasında sigara kullanım sıklığı ve risk faktörleri. Tur Toraks Der. 2009;11:101-6.

18. Kararlı BA. Sigara Bırakma Tedavisinde Kullanılan Yöntemlerin Başarısını Etkileyen Faktörler. Ankara: Gazi Üniversitesi Tıp Fakültesi, Gögüs Hastalıkları Anabilim Dalı, Tıpta Uzmanlık Tezi. 2006.

19. Keskinoğlu P, Sözkesen S, Sarıyer E, Kesik K, Öztürk R. Sosyoekonomik düzeyi düşük bir bölgede 15 yaş üzerinde sigara içicilik sıklığı, içicilik maliyeti ve içiciliğin hastalık varlığına etkisi. Türk Toraks Dergisi. 2007;8:227-33.

20. Grant BF, Harford TC, Dawson DA, Chou PS, Pickering RP. The Alcohol Use Disorder and Associated Disabilities Interview Schedule (AUDADIS): reliability of alcohol and drug modules in a general population sample. Drug and alcohol dependence. 1995;39:37-44.

21. Manley MJ, de Jonge P, Kershaw TS, Desai RA, Lin H, Kasl SV. Association of major depression with subtypes of nicotine dependence found among adult daily smokers: a latent class analysis. Drug and alcohol dependence. 2009;104:126-32.

22. Rezvanfard M, Ekhtiari H, Mokri A, Djavid GE. Psychological and behavioral traits in smokers and their relationship with nicotine dependence level. Archives of Iranian Medicine. 2010;13:395. 